\title{
P-Doped Titania Xerogels as Efficient UV-Visible Photocatalysts
}

\author{
Céline J. Bodson1, Sophie L. Pirard1, René Pirard1', Ludivine Tasseroul', Catherine Bied2, \\ Michel Wong Chi Man², Benoît Heinrichs' ${ }^{1}$, Stéphanie D. Lambert ${ }^{*}$ \\ ${ }^{1}$ Laboratory of Chemical Engineering-Nanomaterials, Catalysis, Electrochemistry, University of Liege, Liege, \\ Belgium \\ ${ }^{2}$ Charles Gerhardt Montpellier Institute (UMR5253 CNRS-UM2-ENSCM-UM1), Montpellier, France \\ Email: ${ }^{*}$ stephanie.lambert@ulg.ac.be
}

Received 15 June 2014; revised 27 July 2014; accepted 6 August 2014

Copyright (C) 2014 by authors and Scientific Research Publishing Inc.

This work is licensed under the Creative Commons Attribution International License (CC BY).

http://creativecommons.org/licenses/by/4.0/

c) (i) Open Access

\begin{abstract}
In the present study, sol-gel process is used to synthesize P-doped $\mathrm{TiO}_{2}$ xerogels by the cogelation method of a functionalized $\mathrm{P}$ alkoxide, $\left(\mathrm{NH}_{2}-\left(\mathrm{CH}_{2}\right)_{2}-\mathrm{NH}-\left(\mathrm{CH}_{2}\right)_{2}-\mathrm{P}(\mathrm{O})-\left(\mathrm{OC}_{2} \mathrm{H}_{5}\right)_{2}\right)$ with $\mathrm{Ti}\left(\mathrm{OC}_{3} \mathrm{H}_{7}\right)_{4}$ in either 2-methoxyethanol or isopropanol. The phosphorus-doping improved the thermal stability of titania and decreased the phase transformation of anatase into rutile. This modification by phosphorus shifted the absorption edge of titania to the visible region as proved by Diffuse reflectance measurements, and thus offers the possibility to produce visible light effective $\mathrm{TiO}_{2}$ photo- $^{-}$ catalyst. The excellent photocatalytic activity of $\mathrm{P}$-doped $\mathrm{TiO}_{2}$ xerogels compared to pure $\mathrm{TiO}_{2}$ could be explained by its high surface area and small $\mathrm{TiO}_{2}$-anatase crystallite size. From these results, it was proved by using three different models that phosphorus intrinsically influences the photocatalytic activity.
\end{abstract}

\section{Keywords}

$\mathrm{TiO}_{2}$ xerogel, Phosphorus-Doping, Sol-Gel, $p$-Nitrophenol Degradation, Photocatalysis

\section{Introduction}

$\mathrm{TiO}_{2}$ heterogeneous photocatalysis is an attractive technique for the complete destruction of undesirable contaminants either in aqueous or gaseous phase by using solar or artificial light illumination [1]-[3]. Upon band gap excitation of $\mathrm{TiO}_{2}$, the photoinduced electrons and positively charged holes can reduce and oxidize the species adsorbed on the $\mathrm{TiO}_{2}$ particles. However $\mathrm{TiO}_{2}$ has several drawbacks among which it can only be activated by

"Corresponding author.

How to cite this paper: Bodson, C.J., Pirard, S.L., Pirard, R., Tasseroul, L., Bied, C., Man, M.W.C., Heinrichs, B. and Lambert, S.D. (2014) P-Doped Titania Xerogels as Efficient UV-Visible Photocatalysts. Journal of Materials Science and Chemical Engineering, 2, 17-32. http://dx.doi.org/10.4236/msce.2014.28004 
UV light due to its large band gap ( $E_{\mathrm{g}}=3.20 \mathrm{eV}$ for anatase) [4] which is energy-consuming and therefore costly. It thus appears interesting to sensitize $\mathrm{TiO}_{2}$ to the whole visible region which may be achieved by doping with non-metallic atoms such as phosphorus [5]. In this case, a new energy band is created, by the combination between $\mathrm{P} 3 p$ and $\mathrm{O} 2 p$ levels, and is located just below the $\mathrm{TiO}_{2}$ conduction band [6]. The band gap energy decreases and hence it is easier to create photoinduced electrons and positively charged holes.

In photocatalysis, the cristallinity and the specific surface area of the catalyst are two very important physicochemical properties. Moreover, there is a close relationship between the adsorption spectrum of the photocatalyst and its efficiency. In the case of $\mathrm{TiO}_{2}$ xerogels, it is possible to transform an amorphous sample into a crystalline one by calcination under air at an adequate temperature. Indeed, an amorphous $\mathrm{TiO}_{2}$ sample, synthesized by the sol-gel process and dried at low temperature $\left(\leq 150^{\circ} \mathrm{C}\right)$, gradually crystallizes into anatase at around $373^{\circ} \mathrm{C}$ [7]. Between $550^{\circ} \mathrm{C}$ and $750^{\circ} \mathrm{C}, \mathrm{TiO}_{2}$-anatase is irreversibly transformed into the less $\mathrm{TiO}_{2}$-rutile photoactive phase [8]. Nevertheless, the temperatures of $\mathrm{TiO}_{2}$ phase transformation (amorphous-anatase and anatase-rutile) are dependent on several parameters: the nature of precursors used for the synthesis [9] [10], the procedure (solgel process, hydrothermal synthesis, chemical vapor deposition...) [11] [12] and the insertion of dopants into the $\mathrm{TiO}_{2}$ matrix [13]-[15].

We recently reported the synthesis of Si-doped and P-doped $\mathrm{TiO}_{2}$ to produce porous xerogels [16]. The P-doped $\mathrm{TiO}_{2}$ were synthesized by the cogelation of titanium isopropoxide $\left(\mathrm{Ti}\left(\mathrm{OC}_{3} \mathrm{H}_{7}\right)_{4}\right.$ called TTIP) with a phosphonate compound (diethyl-(2- $\mathrm{N}$-(2-aminoethyl)aminoethyl)phosphonate, $\mathrm{NH}_{2}-\left(\mathrm{CH}_{2}\right)_{2}-\mathrm{NH}-\left(\mathrm{CH}_{2}\right)_{2}-\mathrm{P}(\mathrm{O})-\left(\mathrm{OC}_{2} \mathrm{H}_{5}\right)_{2}$ called EDAP). In this report, Raman and solid ${ }^{31} \mathrm{P}$ NMR spectroscopies were used to demonstrate the successful formation of Ti-O-P bonds in the dried P-doped titania xerogels. Interestingly it was found that the doping $\mathrm{TiO}_{2}$ with phosphorus not only evidenced a broadening of the absorption band of titania towards the visible range but it also significantly increases the specific surface area of the materials [16].

In the present work, we synthesized and characterized new P-doped $\mathrm{TiO}_{2}$ xerogels which were then used as photocatalysts for the degradation of $p$-nitrophenol. The first part is focused on the TG-DSC measurements in order to determine any changes on phase transition due to the phosphorus incorporation into $\mathrm{TiO}_{2}$ framework. In the second part, the evolution of the physico-chemical properties (specific surface area, cristallinity, absorption properties...) of dried P-doped $\mathrm{TiO}_{2}$ xerogels with the calcination temperature $\left(350^{\circ} \mathrm{C}, 450^{\circ} \mathrm{C}, 550^{\circ} \mathrm{C}\right.$ and $\left.650^{\circ} \mathrm{C}\right)$ is presented. To that purpose, the samples have been characterized by ICP-AES, XRD, nitrogen sorption analyses and DR-UV/Vis measurements. The third part of this study is devoted to the study of the photocatalyic activity of all dried and calcined samples particularly for the degradation of $p$-nitrophenol (PN), a model pollutant, under UV-Vis light. It appears that phosphorus has a strong influence on the photocatatytic activity. Such an influence can be due to either to the influence of phosphorus on surface area, crystallite anatase size, and/or intrinsic influence of Ti-O-P bond formation. To distinguish between both effects, three models were developed to find any correlations between activity and physico-chemical properties.

\section{Experimental}

\subsection{Sample Preparation}

Four gels were synthesized from TTIP $\left(\mathrm{Ti}\left(\mathrm{OC}_{3} \mathrm{H}_{7}\right)_{4}\right)$, EDAP $\left(\mathrm{NH}_{2}-\left(\mathrm{CH}_{2}\right)_{2}-\mathrm{NH}-\left(\mathrm{CH}_{2}\right)_{2}-\mathrm{P}(\mathrm{O})-\left(\mathrm{OC}_{2} \mathrm{H}_{5}\right)_{2}\right)$ in either 2-methoxyethanol or isopropanol as solvent. The synthesis operating variables are presented in Table 1 . The molar dilution ratio, $D=$ [solvent $] /\left([T T I P]+[\right.$ EDAP $]$ ), and the molar hydrolysis ratio, $H=\left[\mathrm{H}_{2} \mathrm{O}\right] /([\mathrm{TTIP}]+$ $1 / 2$ [EDAP]), were fixed to 20 and 2 respectively for all the samples. For each sample, Met or Iso denotes the solvent used for the synthesis, respectively 2-methoxyethanol and isopropanol; $\mathrm{TiP} / \mathrm{X}$ denotes $\mathrm{TiO}_{2}$ xerogels synthesized with EDAP and for which, $\mathrm{X}$ is the molar [EDAP]/[TTIP] ratio. Pure $\mathrm{TiO}_{2}$ xerogel synthesized in 2-methoxyethanol is denoted Met- $\mathrm{TiO}_{2}$ and was synthesized as blank material for comparison with the P-doped xerogels.

All the syntheses were performed under inert atmosphere $\left(\mathrm{N}_{2}\right)$ according to the following steps: 1$)$ after mixing EDAP in half of the total volume of solvent, the slurry was stirred at room temperature for $10 \mathrm{~min}$; 2) then the mixture of TTIP and water in the remaining half of the total ethanol volume was slowly added to the EDAP mixture under vigorous stirring. The volume of the final solutions was $125 \mathrm{~mL}$. The vessel was then tightly closed and heated up to $60^{\circ} \mathrm{C}$ for $24 \mathrm{~h}$ (gelling and ageing [17]).

Gel time $\left(t_{\mathrm{g}}\right)$ is the time elapsed from the introduction of the last reactant in the solution until gelation occured 
Table 1. Synthesis operating variables of P-doped $\mathrm{TiO}_{2}$ xerogels.

\begin{tabular}{cccccccc}
\hline Sample & $\begin{array}{c}n_{\text {EDAP }} \\
(\mathrm{mmol})\end{array}$ & $\begin{array}{c}n_{\text {TTIP }} \\
(\mathrm{mmol})\end{array}$ & $\begin{array}{c}n_{\mathrm{H}_{2} \mathrm{O}} \\
(\mathrm{mmol})\end{array}$ & $\begin{array}{c}n_{\text {solvent }}{ }^{\mathrm{a}} \\
(\mathrm{mmol})\end{array}$ & $\begin{array}{c}\text { Theoretical } \\
\text { [EDAP]/[TTIP] } \\
(\mathrm{mol} / \mathrm{mol})\end{array}$ & $\begin{array}{c}\text { Actual } \\
\text { [EDAP]/[TTIP] } \\
(\mathrm{mol} / \mathrm{mol})\end{array}$ & $\begin{array}{c}t_{\mathrm{g}}^{\mathrm{b}} \\
(\mathrm{min})\end{array}$ \\
\hline Met-TiO 2 & - & 65.0 & 130 & 1330 & - & - & 8 \\
Met-TiP/0.01 & 0.61 & 67.2 & 130 & 1330 & 0.01 & 0.009 & 18 \\
Met-TiP/0.1 & 6.09 & 62.2 & 130 & 1330 & 0.10 & 0.114 & 28 \\
Iso-TiP/0.1 & 6.09 & 62.2 & 130 & 1331 & 0.10 & 0.097 & 12 \\
\hline
\end{tabular}

${ }^{\mathrm{a}} n_{\text {solvent }}$ is 2-methoxyethanol or isopropanol. ${ }^{\mathrm{b}}$ measured by ICP-AES. ${ }^{\mathrm{c}} \mathrm{t}_{\mathrm{g}}$ is the gel time.

and was performed in an oven at $60^{\circ} \mathrm{C}$. Gelation is defined as the point when the liquid does not flow anymore when the flask is tipped at an angle of $45^{\circ}$.

The wet gels were dried under vacuum according to the following procedure: the flasks were opened and placed into a drying oven at $60^{\circ} \mathrm{C}$, and the pressure was slowly decreased (to prevent gel bursting) to the minimum value of $1200 \mathrm{~Pa}$ after $48 \mathrm{~h}$. The drying oven was then heated at $150^{\circ} \mathrm{C}$ for $24 \mathrm{~h}$ leading to xerogels [17].

Each sample is divided in four parts with the same mass. Each part is calcined at a different temperature, i.e. $350^{\circ} \mathrm{C}, 450^{\circ} \mathrm{C}, 550^{\circ} \mathrm{C}$ and $650^{\circ} \mathrm{C}$, as follows: the sample was heated up to the desired temperature at a rate of $150^{\circ} \mathrm{C} / \mathrm{h}$ under flowing air $\left(0.0074 \mathrm{~mol} \cdot \mathrm{s}^{-1}\right)$; this temperature was maintained for $5 \mathrm{~h}$ in air (flow rate: 0.02 $\left.\mathrm{mol} \cdot \mathrm{s}^{-1}\right)$. Calcined samples are denoted Met-TiP/X-T or Iso-TiP/X-T, where $\mathrm{T}$ is the calcination temperature of the sample. For example, Met TiP/0.1-550 is a P-doped $\mathrm{TiO}_{2}$ xerogel synthesized in 2-methoxyethanol, with a molar [EDAP] $/[\mathrm{TTIP}]$ ratio $=0.1$, and calcined at $550^{\circ} \mathrm{C}$ under air for $5 \mathrm{~h}$.

\subsection{Sample Characterization}

Inductively coupled plasma-atomic emission spectroscopy (ICP-AES), equipped with an ICAP 6500 THERMO Scientific device was used to determine the molar [EDAP]/[TTIP] ratio of the dried and calcined samples of P-doped $\mathrm{TiO}_{2}$ xerogels. Solutions for analysis were prepared as follows: 1) $2 \mathrm{~g}$ of $\mathrm{Na}_{2} \mathrm{O}_{2}, 1 \mathrm{~g}$ of $\mathrm{NaOH}$ and $0.1 \mathrm{~g}$ of sample were mixed in a vitreous carbon crucible; 2) the mixture was heated beyond the melting point (up to $950^{\circ} \mathrm{C}$ ); 3) after cooling and solidification, the mixture was digested in $30 \mathrm{~mL}$ of $\mathrm{HNO}_{3}(65 \%)$; 4) the solution was then transferred into a $500 \mathrm{~mL}$ calibrated flask that was finally filled with deionized water. The measured molar [EDAP]/[TTIP] ratio for dried P-doped $\mathrm{TiO}_{2}$ xerogels are given in Table 1 and the measured molar [EDAP]/[TTIP] ratio for calcined P-doped $\mathrm{TiO}_{2}$ xerogels are given in Table 2.

TG-DSC measurements were realized under helium between $40^{\circ} \mathrm{C}$ and $700^{\circ} \mathrm{C}$, with a heating rate of $0.16^{\circ} \mathrm{C} \cdot \mathrm{s}^{-1}$, using a Setaram TG-DSC 111 device, according to the following procedure: 1) a precise amount of sample was placed into a platinum crucible; 2) the sample was heated under helium from $40^{\circ} \mathrm{C}$ to $700^{\circ} \mathrm{C}$; 3) the sample was cooled and was weighed again.

X-ray diffraction (XRD) patterns were recorded with a Siemens D5000 powder diffractometer $\left(\mathrm{Cu}-\mathrm{K}_{\alpha}\right.$ radiation) between $20^{\circ}$ and $65^{\circ}(2 \theta)$. The size of $\mathrm{TiO}_{2}$-anatase particles, $d_{\mathrm{a}}$, was estimated from X-ray peak broadening by the Scherrer method [18].

Nitrogen adsorption-desorption isotherms were measured at $-196^{\circ} \mathrm{C}$ on a Fisons Sorptomatic 1990 after outgassing $\left(10^{-5} \mathrm{~Pa}\right)$ for $24 \mathrm{~h}$ at room temperature.

Diffuse reflectance measurements in the UV/Vis region (250 - $800 \mathrm{~nm}$ ) (DR-UV/Vis) were performed on a Varian Cary 5000 UV/Vis/NIR spectrophotometer, equipped with a Varian External DRA-2500 integrating sphere, using $\mathrm{BaSO}_{4}$ as reference. Samples have been prepared by immobilizing the powder between a PVC support and a quartz glass. UV/Vis spectra were recorded in diffuse reflectance mode ( $R=$ reflection intensity) and transformed to the absorbance coefficient $(\mathrm{F}(R))$ by the Kubelka-Munk function [19], $\mathrm{F}(R)=(1-R)^{2} / 2 R$. The illuminated surface is the same for all samples. For the sake of comparison, all spectra were arbitrary normalized in intensity to 1.0 by dividing each spectrum by their maximum. The band gap has been determined from the Tauc plot $[20](\mathrm{F}(R) \mathrm{h} v)^{1 / 2}$ versus $\mathrm{h} v$.

\subsection{Photocatalytic Tests}

The photoactivity of the xerogels was compared by evaluating the relative residual concentration of $p$-nitro- 
Table 2. Actual molar [EDAP]/[TTIP] ratio measured by ICP-AES for P-doped $\mathrm{TiO}_{2}$ xerogels.

\begin{tabular}{cc}
\hline Sample & [EDAP]/[TTIP] (mol/mol) \\
Met-TiP/0.01 & 0.0089 \\
Met-TiP/0.01-350 & 0.0088 \\
Met-TiP/0.01-450 & 0.0087 \\
Met-TiP/0.01-550 & 0.0028 \\
Met-TiP/0.01-650 & 0.0056 \\
Met-TiP/0.1 & 0.1145 \\
Met-TiP/0.1-350 & 0.1098 \\
Met-TiP/0.1-450 & 0.1123 \\
Met-TiP/0.1-550 & 0.0710 \\
Met-TiP/0.1-650 & 0.0724 \\
Iso-TiP/0.1 & 0.0971 \\
Iso-TiP/0.1-350 & 0.0982 \\
Iso-TiP/0.1-450 & 0.0964 \\
Iso-TiP/0.1-550 & 0.0932 \\
Iso-TiP/0.1-650 & 0.0246 \\
\hline
\end{tabular}

phenol (PN) after $6 \mathrm{~h}$ under the halogen lamp. The photocatalytic degradation of PN was carried out using a batch reactor with an external halogen lamp (Philips $300 \mathrm{~W}, 240 \mathrm{~V}$ ). A circulating water jacket was used to cool the batch reactor and the temperature was kept at $23^{\circ} \mathrm{C}$. The photocatalytic degradation of PN was realized in 8 closed tubes disposed in water around the lamp. Each suspension (volume $=15 \mathrm{~mL}$ ) in each tube was mixed under vigorous stirring.

In a typical experiment, the catalyst was added to $15 \mathrm{~mL}$ aqueous solution of PN (Initial concentration, $C_{\mathrm{i}}$, is equal to $10^{-4} \mathrm{~mol} \cdot \mathrm{L}^{-1}$ ) to reach a concentration of $1 \mathrm{~g} \cdot \mathrm{L}^{-1}$. To degrade only the protonated form of $\mathrm{PN}\left(\mathrm{pK}_{\mathrm{a}}=\right.$ 7.2), the solution $\mathrm{pH}$ was fixed at 3.5 by adding a few $\mu \mathrm{L}$ of $1 \mathrm{~N} \mathrm{HCl}$ aqueous solution. The shaking of the suspension was controlled during the photocatalytic test to ensure that the suspension was homogeneous. Time 0 corresponds to the switching on of the lamp. After $6 \mathrm{~h}, 2 \mathrm{~mL}$ of each suspension were sampled with a syringe and filtered in order to separate the xerogel powder from the $p$-nitrophenol solution. In those experimental conditions, the $\mathrm{pH}$ of the filtered $p$-nitrophenol solution was equal to 4 . Therefore, only the protonated form of $p$ nitrophenol was present in the solution. The final concentration of that protonated form of $p$-nitrophenol, $C_{\mathrm{f}}$, was measured by UV/Vis spectroscopy (Genesys 10S UV-Vis, Thermo Scientific) at $318 \mathrm{~nm}$. The photocatalytic activity of samples was calculated from the percentage of PN degraded after 6 h, $A$, and given by Equation (1):

$$
A=\left(C_{\mathrm{i}}-C_{\mathrm{f}}\right) / C_{\mathrm{i}} \times 100
$$

where $C_{\mathrm{i}}$ is the initial PN concentration and $C_{\mathrm{f}}$ is the final PN concentration after $6 \mathrm{~h}$. The same experimental protocol was applied to a solution containing PN only, that is without xerogel under light and to PN solution containing each xerogel successively but without light to ensure that the relative residual concentration obtained corresponds really only to the photodegradation of $\mathrm{PN}$ by pure $\mathrm{TiO}_{2}$ and $\mathrm{P}$-doped $\mathrm{TiO}_{2}$ xerogels under halogen lamp. Each measurement was repeated three times.

\subsection{Parameters Estimation and Statistical Testing of Models}

The fitting of kinetic models was performed by applying the Gauss-Newton optimization method by using a statistical Fisher F-test [21] [22]. NLPE software, Non Linear Parameter Estimation, from IBM was used [23].

\section{Results}

\subsection{Thermogravimetric Behaviour of Pure $\mathrm{TiO}_{2}$ and $\mathrm{P}$-Doped $\mathrm{TiO}_{2}$ Xerogels}

In Figure 1(a), TG-DSC curves are presented for the sample Met- $\mathrm{TiO}_{2}$. A weight loss of about $20 \%$ associated 


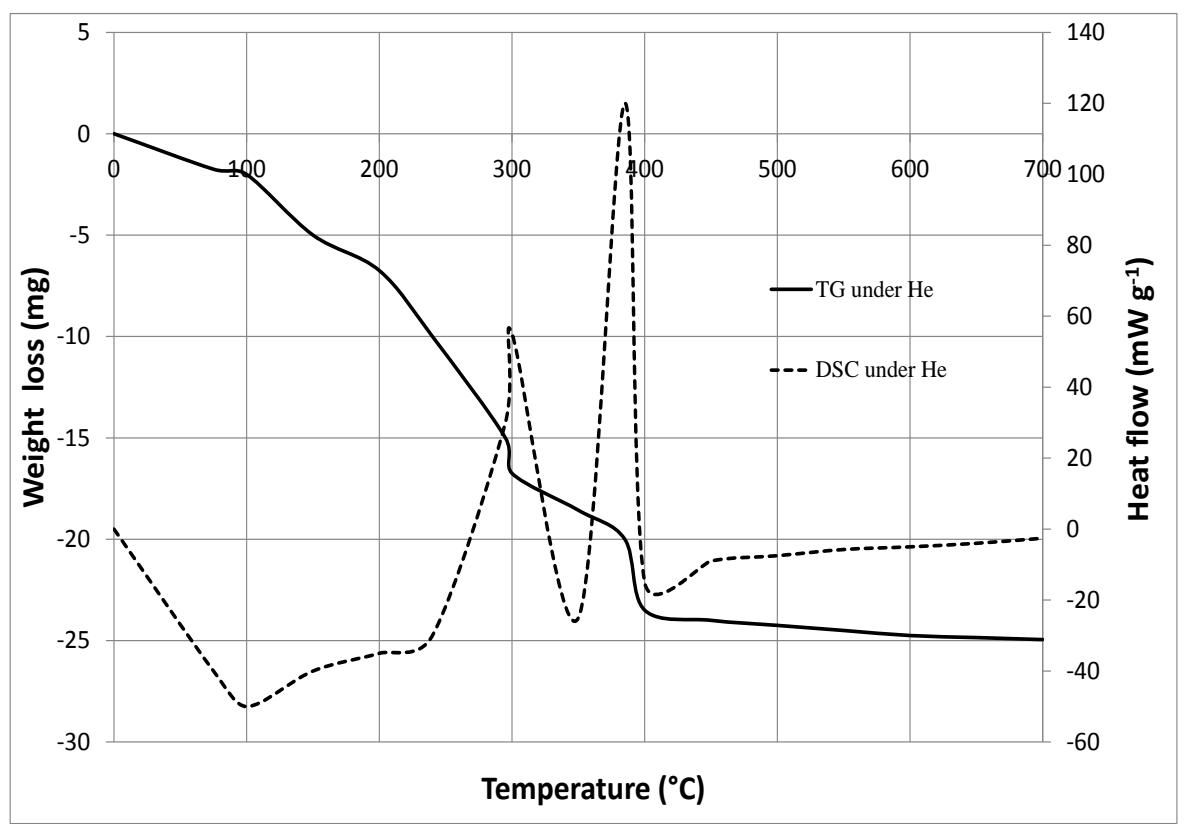

(a)

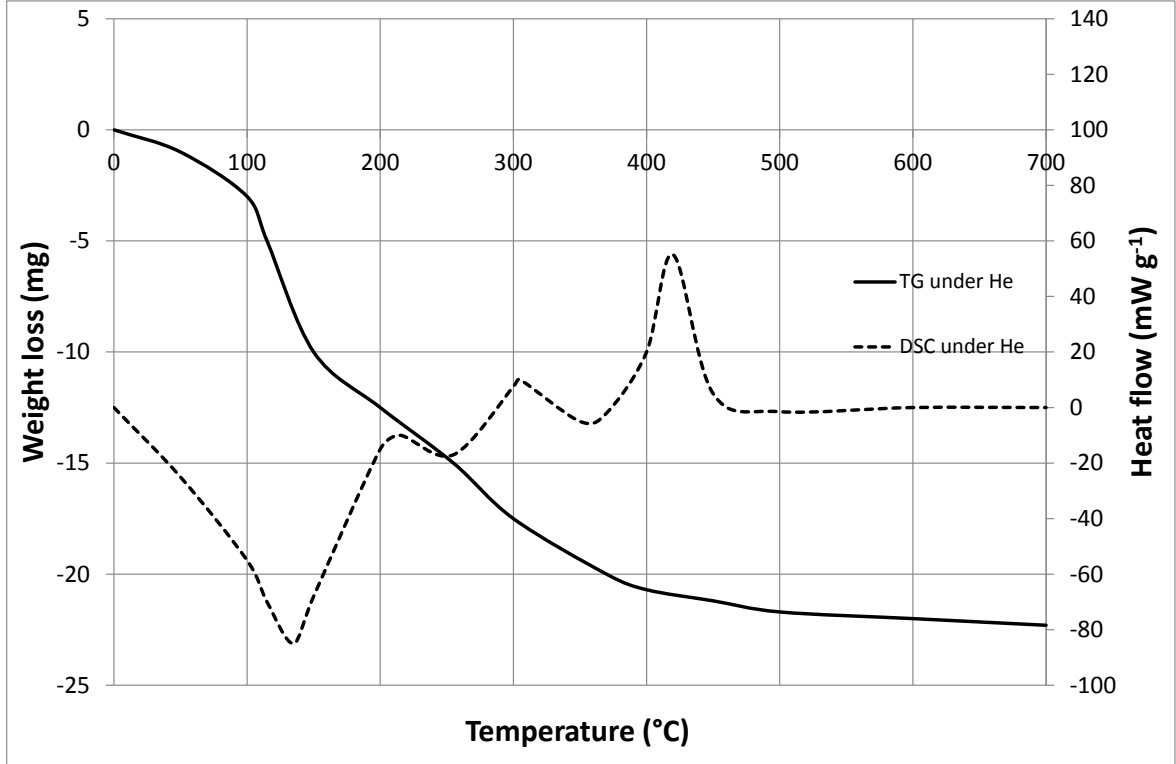

(b)

Figure 1. TG-DSC curves of (a) sample Met- $\mathrm{TiO}_{2}$ (initial weight $=73.2 \mathrm{mg}$ ) and (b) sample Met-TiP/0.01 (initial weight $=70 \mathrm{mg}$ ).

to a large endothermic peak is observed between $50^{\circ} \mathrm{C}$ and $250^{\circ} \mathrm{C}$, corresponding to the evaporation of 2-methoxyethanol and water. The weight loss (for a total of about $28 \%$ ) extends to $450^{\circ} \mathrm{C}$ with two exothermic phenomena at $300^{\circ} \mathrm{C}$ and $385^{\circ} \mathrm{C}$. In that temperature range it is known that the condensation reactions occur in the solid and thus these exothermic phenomena can be attributed to the condensation between hydroxyl groups or between hydroxyl groups and remaining alkoxy groups associated to the formation of water or alcohol and to the weight losses [24].

Moreover, the cristallization of amorphous $\mathrm{TiO}_{2}$ into anatase is also an exothermic phenomenon which occurs at around $373^{\circ} \mathrm{C}$ [7]. The peak corresponding to this transformation probably overlaps with the second peak at $385^{\circ} \mathrm{C}$ and associated to one of the condensation reactions. 
Figure 1(b) represents the TG-DSC curves of the sample Met-TiP/0.01. A weight loss of about $20 \%$ associated to a large endothermic peak is observed between $30^{\circ} \mathrm{C}$ and $210^{\circ} \mathrm{C}$, corresponding to the evaporation of 2-methoxyethanol and water. The weight loss (for a total of about $32 \%$ ) extends to $500^{\circ} \mathrm{C}$ with one endothermic peak at $250^{\circ} \mathrm{C}$ following by two exothermic phenomena at $300^{\circ} \mathrm{C}$ and $410^{\circ} \mathrm{C}$. The endothermic peak at $250^{\circ} \mathrm{C}$ could correspond to residual 2-methoxyethanol pyrolysis. As in the former case, both exothermic peaks are attributed to the condensation reactions [25]. Nevertheless, the first exothermic peak at $300^{\circ} \mathrm{C}$ is smaller in Figure 1 (b) than in Figure 1(a). This peak mitigation could correspond to the formation of $\mathrm{P}_{2} \mathrm{O}_{5}$ species from EDAP, which sublimes at around $300^{\circ} \mathrm{C}$ and which is an endothermic phenomenon [24]. Moreover, the second exothermic peak at $420^{\circ} \mathrm{C}$ could correspond to the cristallization of amorphous $\mathrm{TiO}_{2}$ into anatase, but with a delay of about $40^{\circ} \mathrm{C}$.

Both samples Met-TiP/0.1 and Iso-TiP/0.1 (curves not shown) exhibit similar TG-DSC curves under He as sample Met-TiP/0.01. Nevertheless, the second exothermic peak appears at markedly higher temperature $\left(550^{\circ} \mathrm{C}\right)$ instead of $420^{\circ} \mathrm{C}$ for sample Met-TiP/0.01 and instead of $385^{\circ} \mathrm{C}$ for sample Met- $\mathrm{TiO}_{2}$. We may thus conclude that the presence of phosphorus into $\mathrm{TiO}_{2}$ matrix delays the crystallization of amorphous $\mathrm{TiO}_{2}$ into anatase, an incremental crystallization delay being observed with increasing phosphorus loading.

\subsection{X-Ray Diffraction of Pure $\mathrm{TiO}_{2}$ and $\mathrm{P}$-Doped $\mathrm{TiO}_{2}$ Xerogels}

The effect of calcination temperature on sample crystallinity was investigated by X-ray diffraction. The XRD patterns of the sample $\mathrm{Met}_{-\mathrm{TiO}_{2}}$ (curves not shown) display only anatase reflections (JCPDS 21-1272: $2 \theta=$ $25.3^{\circ}, 37.9^{\circ}, 48.0^{\circ}, 54.6^{\circ}$ et $62.8^{\circ}$ ) after calcination at $350^{\circ} \mathrm{C}, 450^{\circ} \mathrm{C}$ and $550^{\circ} \mathrm{C}$. When the sample $\mathrm{Met}^{-} \mathrm{TiO}_{2}$ is heated up to $650^{\circ} \mathrm{C}$, it undergoes a phase transition from anatase structure to rutile structure (JCPDS 21-1276: $2 \theta$ $=27.3^{\circ}, 35.9^{\circ}, 41.1^{\circ}$ et $54.1^{\circ}$ ) as already reported in literature [15].

The XRD patterns of sample Met-TiP/ 0.01 calcined at $350^{\circ} \mathrm{C}, 450^{\circ} \mathrm{C}, 550^{\circ} \mathrm{C}$ and $650^{\circ} \mathrm{C}$ are presented in Figure 2 and exemplifies those of samples Met-TiP/0.01, Met-TiP/0.1 and Iso-TiP/0.1 which follow the same trend. After calcination at $350^{\circ} \mathrm{C}$ and $450^{\circ} \mathrm{C}$, the sample Met-TiP/0.01 is always amorphous. When the calcination temperature is $\geq 550^{\circ} \mathrm{C}$, the characteristic peaks of anatase structure appear on the patterns. Nevertheless, even after a calcination at $650^{\circ} \mathrm{C}$ for $5 \mathrm{~h}$, no rutile structure appears on the patterns of samples Met-TiP/0.01, Met-TiP/0.1 and Iso-TiP/0.1.

The $\mathrm{TiO}_{2}$ anatase crystallite sizes, $d_{\mathrm{a}}$, calculated by the Scherrer equation from peak broadening [18] are presented in Table 3 for all the samples. It is observed that $d_{\mathrm{a}}$ increases with the calcination temperature. Interestingly, by comparing samples Met-TiP/0.01 with Met-TiP/0.1, it is obvious that the nanoparticle size, $d_{\mathrm{a}}$, increases more slowly, and thus the cristallization of amorphous $\mathrm{TiO}_{2}$ into anatase structure is more delayed in the latter case with a higher phosphorus loading increases. This is confirmed with sample Iso-TiP/0.1 which exhibits similar sizes as Met-TiP/0.1.

\subsection{Nitrogen Adsorption-Desorption Isotherms of P-Doped $\mathrm{TiO}_{2}$ Xerogels}

The textural properties of P-doped $\mathrm{TiO}_{2}$ xerogels are reported in Table 4. Those of sample Met- $\mathrm{TiO}_{2}$ are not given in this table because it is not porous $\left(S_{\mathrm{BET}}<5 \mathrm{~m}^{2} \cdot \mathrm{g}^{-1}\right)$ whichever the calcination temperature $\left(350^{\circ} \mathrm{C}\right.$, $450^{\circ} \mathrm{C}, 550^{\circ} \mathrm{C}$ and $650^{\circ} \mathrm{C}$ ).

In Figure 3(a), nitrogen adsorption-desorption isotherms of sample Met-TiP/0.01 dried and calcined at $350^{\circ} \mathrm{C}$, $450^{\circ} \mathrm{C}, 550^{\circ} \mathrm{C}$ and $650^{\circ} \mathrm{C}$ are presented. Like sample Met- $\mathrm{TiO}_{2}$, the dried sample Met-TiP/0.01 is not porous. One reason could be the presence of the organic aminoethylaminopropyl chain of EDAP in the pores thus reducing accessibility to the latter ones and this is also shown in Table 4 with a specific surface area, $S_{\mathrm{BET}}$, of $<5$ $\mathrm{m}^{2} \cdot \mathrm{g}^{-1}$. After calcination under air at $350^{\circ} \mathrm{C}$, the isotherm of the resulting sample Met-TiP/0.01-350 exhibits a narrow adsorption-desorption hysteresis loop for $p / p_{0}$ values between 0.4 and 0.6 characteristic of capillary condensation in small mesopores (2 - $10 \mathrm{~nm})$ [26]. Indeed, in Table 4, the specific surface area obtained from the Broekhoff-de-Boer theory and characteristic of the presence of mesopores, $S_{\mathrm{BdB}}$, is equal to $90 \mathrm{~m}^{2} \cdot \mathrm{g}^{-1}$, while $S_{\mathrm{BET}}$ of this sample is equal to $115 \mathrm{~m}^{2} \cdot \mathrm{g}^{-1}$ showing that sample Met-TiP/0.01-350 is essentially mesoporous. Nevertheless, this sample is also slightly microporous because the microporous volume calculated from the Dubinin-Raduskevitch theory, $V_{\mathrm{DR}}$, is equal to $0.04 \mathrm{~cm}^{3} \cdot \mathrm{g}^{-1}$. Upon calcination under air at $450^{\circ} \mathrm{C}$ (Figure 3(a)), the adsorption-desorption hysteresis loop is shifted towards higher $p / p_{0}$ values, resulting from an increase of the size of the mesopores [26]. In Table 4, $S_{\mathrm{BET}}$ and $S_{\mathrm{BdB}}$ for the sample Met-TiP/0.01-450 decrease down to $65 \mathrm{~m}^{2} \cdot \mathrm{g}^{-1}$ 


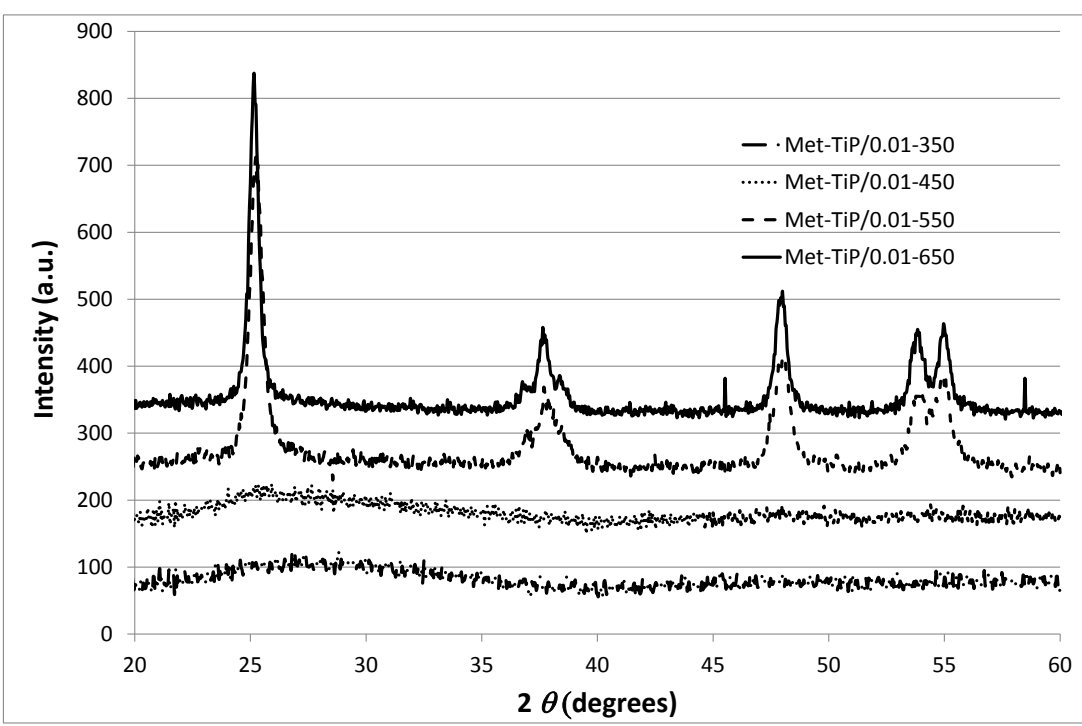

Figure 2. X-ray diffraction patterns of sample Met-TiP/0.01-T calcined at $350^{\circ} \mathrm{C}$, $450^{\circ} \mathrm{C}, 550^{\circ} \mathrm{C}$ and $650^{\circ} \mathrm{C}$.

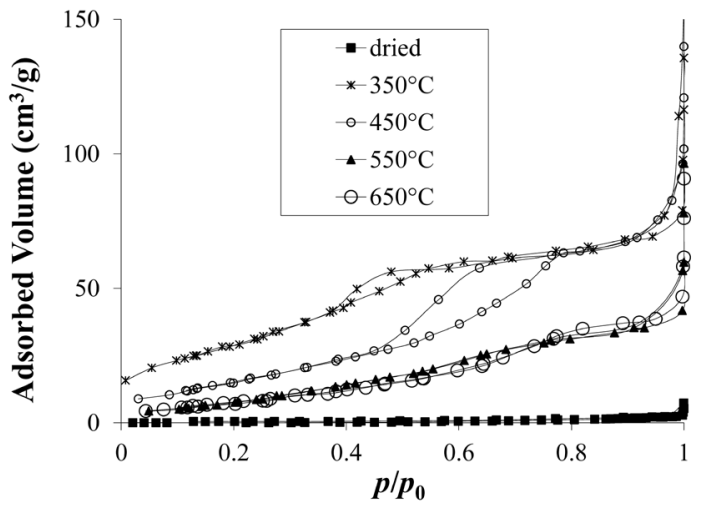

(a)

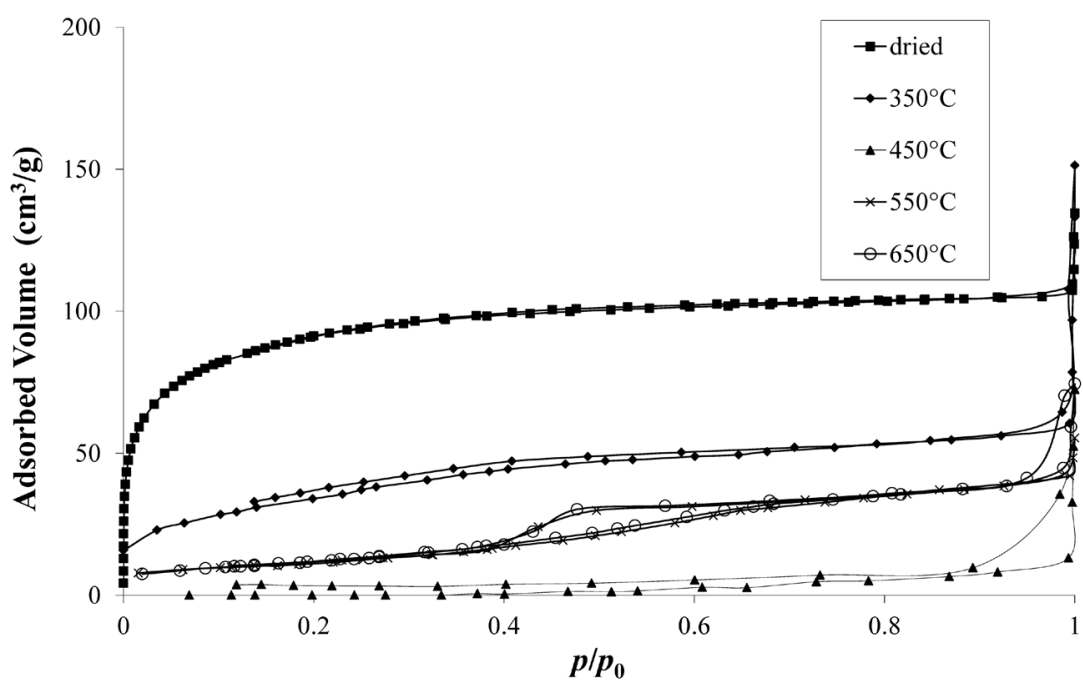

(b)

Figure 3. Nitrogen adsorption-desorption isotherms of (a) sample Met-TiP/0.01-T and (b) sample Iso-TiP/0.1-T. 
Table 3. $\mathrm{TiO}_{2}$ anatase crystallite sizes as a function of calcination temperature.

\begin{tabular}{ccccc}
\hline \multirow{2}{*}{$\begin{array}{c}\text { Calcination temperature } \\
\left({ }^{\circ} \mathrm{C}\right)\end{array}$} & \multicolumn{4}{c}{$d_{\mathrm{a}}(\mathrm{nm})$} \\
\cline { 2 - 5 } & ${\mathrm{Met}-\mathrm{TiO}_{2}}^{3}$ & Met-TiP/0.01 & Met-TiP/0.1 & Iso-TiP/0.1 \\
450 & 8 & $-{ }^{\mathrm{a}}$ & $-^{\mathrm{a}}$ & $-^{\mathrm{a}}$ \\
550 & 11 & 6 & 6 & $-^{\mathrm{a}}$ \\
650 & 24 & 15 & 8 & 9 \\
\hline
\end{tabular}

${ }^{a}$ not measurable; $\mathrm{R}=$ rutile.

Table 4. Textural properties of P-doped $\mathrm{TiO}_{2}$ xerogels.

\begin{tabular}{|c|c|c|c|c|c|}
\hline Sample & $\begin{array}{c}S_{\mathrm{BET}} \\
\pm 5 \\
\left(\mathrm{~m}^{2} \cdot \mathrm{g}^{-1}\right)\end{array}$ & $\begin{array}{c}S_{\mathrm{t}} \\
\pm 5 \\
\left(\mathrm{~m}^{2} \cdot \mathrm{g}^{-1}\right)\end{array}$ & $\begin{array}{c}S_{\mathrm{BdB}} \\
\pm 5 \\
\left(\mathrm{~m}^{2} \cdot \mathrm{g}^{-1}\right)\end{array}$ & $\begin{array}{c}V_{\mathrm{p}} \\
\pm 0.1 \\
\left(\mathrm{~cm}^{3} \cdot \mathrm{g}^{-1}\right)\end{array}$ & $\begin{array}{c}V_{\mathrm{DR}} \\
\pm 0.01 \\
\left(\mathrm{~cm}^{3} \cdot \mathrm{g}^{-1}\right)\end{array}$ \\
\hline Met-TiP/0.01 & $<5$ & $<5$ & $-{ }^{a}$ & $<0.1$ & $-{ }^{a}$ \\
\hline Met-TiP/0.01-350 & 115 & 115 & 90 & 0.2 & 0.04 \\
\hline Met-TiP/0.01-450 & 65 & 70 & 55 & 0.2 & 0.03 \\
\hline Met-TiP/0.01-550 & 40 & 40 & 35 & 0.1 & 0.02 \\
\hline Met-TiP/0.01-650 & 35 & 35 & 35 & 0.1 & 0.01 \\
\hline Met-TiP/0.1 & $<5$ & $<5$ & $<5$ & $<0.1$ & $-{ }^{\mathrm{a}}$ \\
\hline Met-TiP/0.1-350 & $<5$ & $<5$ & $<5$ & $<0.1$ & $-{ }^{\mathrm{a}}$ \\
\hline Met-TiP/0.1-450 & 70 & 70 & 55 & 0.1 & 0.03 \\
\hline Met-TiP/0.1-550 & 105 & 105 & 85 & 0.1 & 0.04 \\
\hline Met-TiP/0.1-650 & 90 & 95 & 75 & 0.2 & 0.04 \\
\hline Iso-TiP/0.1 & 340 & 355 & 100 & 0.2 & 0.13 \\
\hline Iso-TiP/0.1-350 & 125 & 125 & 45 & 0.2 & 0.06 \\
\hline Iso-TiP/0.1-450 & $<5$ & $<5$ & $<5$ & 0.2 & $-{ }^{a}$ \\
\hline Iso-TiP/0.1-550 & 40 & 45 & 30 & 0.1 & 0.02 \\
\hline Iso-TiP/0.1-650 & 45 & 45 & 30 & 0.1 & 0.02 \\
\hline
\end{tabular}

${ }^{a}$ not measurable. $S_{\mathrm{BET}}$ : specific surface area obtained by BET method; $S_{\mathrm{t}}$ : specific surface area obtained from the slope before the downward deviation in the $t$-plot; $S_{\mathrm{BdB}}$ : specific surface area obtained from the Broekhoff-deBoer theory; $V_{\mathrm{p}}$ : specific liquid volume adsorbed at saturation pressure of nitrogen; $V_{\mathrm{DR}}$ : microporous volume calculated from the Dubinin-Raduskevitch theory.

and $55 \mathrm{~m}^{2} \cdot \mathrm{g}^{-1}$ respectively. Their decrease could be due to the beginning of the crystallization of amorphous $\mathrm{TiO}_{2}$ into anatase (Figure 2) [15]. After calcination at $550^{\circ} \mathrm{C}$ and $650^{\circ} \mathrm{C}$, mesoporosity is partly maintained but microporosity disappears with similar values of $S_{\mathrm{BET}}$ and $S_{\mathrm{BdB}}$ (Table 4). These samples still present $S_{\mathrm{BET}}$ values around $35-40 \mathrm{~m}^{2} \cdot \mathrm{g}^{-1}$.

The data from Table 4, show that samples of dried Met-TiP/0.1 and Met-TiP/0.1-350 are not porous $\left(S_{\mathrm{BET}}<5\right.$ $\left.\mathrm{m}^{2} \cdot \mathrm{g}^{-1}\right)$. After calcination at $450^{\circ} \mathrm{C}$, porosity appears within the sample with $S_{\mathrm{BET}}$ and $S_{\mathrm{BdB}}$ reaching $70 \mathrm{~m}^{2} \cdot \mathrm{g}^{-1}$ and $55 \mathrm{~m}^{2} \cdot \mathrm{g}^{-1}$ respectively. Further calcination to $550^{\circ} \mathrm{C}$, results in an increase of $S_{\mathrm{BET}}$ and $S_{\mathrm{BdB}}$ to $105 \mathrm{~m}^{2} \cdot \mathrm{g}^{-1}$ and $85 \mathrm{~m}^{2} \cdot \mathrm{g}^{-1}$ respectively. At this temperature, the anatase structure is not yet well developed (Table 3 , in which $d_{\mathrm{a}}$ is equal to $8 \mathrm{~nm}$ ). Upon calcination at $650^{\circ} \mathrm{C}, S_{\mathrm{BET}}$ and $S_{\mathrm{BdB}}$ slightly decrease to $90-95 \mathrm{~m}^{2} \cdot \mathrm{g}^{-1}$. Indeed, in Table 3, $d_{\mathrm{a}}$ gradually increases because the crystallization of amorphous $\mathrm{TiO}_{2}$ into anatase structure starts at this stage. The comparison between samples Met-TiP/0.01 and Met-TiP/0.1 shows that the crystallization of amorphous $\mathrm{TiO}_{2}$ into anatase structure is shifted towards higher temperatures when the phosphorus loading increases, and correlate with the TG-DSC measurements (see 3.1).

In Figure 3(b), nitrogen adsorption-desorption isotherms of samples Iso-TiP/0.1 dried and calcined at $350^{\circ} \mathrm{C}$, $450^{\circ} \mathrm{C}, 550^{\circ} \mathrm{C}$ and $650^{\circ} \mathrm{C}$ are presented. The dried sample Iso-TiP/ $/ 0.1$ presents at low relative pressure, a sharp increase of the adsorbed volume, followed by a plateau which corresponds to type I isotherm according to BDDT 
classification [26], which is characteristic of microporous adsorbents. Compared with samples Met-TiP/0.01 and Met-TiP/0.1, the specific surface area, $S_{\mathrm{BET}}$, of the dried sample Iso-TiP/0.1 (Table 4) is significantly high (340 $\mathrm{m}^{2} \cdot \mathrm{g}^{-1}$ ). Nevertheless, after calcination at $350^{\circ} \mathrm{C}, S_{\mathrm{BET}}, S_{\mathrm{BdB}}$, and $V_{\mathrm{DR}}$ strongly decrease and the calcination at $450^{\circ} \mathrm{C}$ induces the collapse of the texture of the sample with very low surface area $\left(S_{\mathrm{BET}}<5 \mathrm{~m}^{2} \cdot \mathrm{g}^{-1}\right)$. After calcination at $550^{\circ} \mathrm{C}$ and $650^{\circ} \mathrm{C}$, amorphous $\mathrm{TiO}_{2}$ crystallizes into anatase structure with $d_{\mathrm{a}}$ equal to 9 and $11 \mathrm{~nm}$ respectively (Table 3). In this case, $S_{\mathrm{BET}}$ of samples Iso-TiP/0.1-550 and Iso-TiP/0.1-650 is equal to around 40 $45 \mathrm{~m}^{2} \cdot \mathrm{g}^{-1}$, and the isotherms exhibit similar narrow adsorption-desorption hysteresis loop for $p / p_{0}$ values between 0.4 and 0.6 . This hysteresis is characteristic of capillary condensation in small mesopores (2 - $10 \mathrm{~nm})$ [26], located between $\mathrm{TiO}_{2}$ crystallites [15].

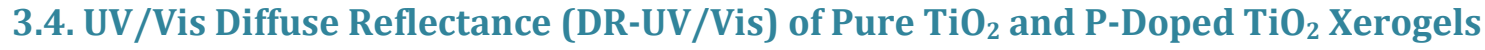

The DR-UV/Vis spectra of some calcined samples (Met-TiO ${ }_{2}-650$, Met-TiP/0.01-550, Met-TiP/0.1-550 and Met-TiP/0.1-650) are given in Figure 4: the other samples calcined at $550^{\circ} \mathrm{C}$ and $650^{\circ} \mathrm{C}$ are not shown as they are very similar. The DR-UV/Vis spectra of those samples of Met-TiO ${ }_{2}$, Met-TiP/0.01, Met-TiP/0.1 and IsoTiP/0.1 calcined at $350^{\circ} \mathrm{C}$ and $450^{\circ} \mathrm{C}$ are not considered since they still contain a lot of organic moieties as illustrated by their coloured feature. Thus, it is difficult to analyze the DR-UV/Vis spectra of these samples because their absorption in the visible range is higher than the samples calcined at $550^{\circ} \mathrm{C}$ and $650^{\circ} \mathrm{C}$ [27].

Figure 4 clearly demonstrates that the introduction of phosphorus into $\mathrm{TiO}_{2}$ matrix induces a shift of the $\mathrm{TiO}_{2}$ maximal absorption band from $335 \mathrm{~nm}$ (Met-TiO2-650) to $370 \mathrm{~nm}$ for all the EDAP-containing samples calcined at $550^{\circ} \mathrm{C}$ and $650^{\circ} \mathrm{C}$. The molar [EDAP]/[TTIP] ratio (0.01 or 0.1) and the solvent (2-methoxyethanol or isopropanol) have no significant influence on the DR-UV/Vis spectra of the $\mathrm{P}$-doped $\mathrm{TiO}_{2}$ xerogels.

The calculated band gap energy values are reported in Table 5. All P-doped $\mathrm{TiO}_{2}$ xerogels have a smaller band gap energy values $(3.03-3.10 \mathrm{eV}$ ) than those of samples Met-TiO2-550 and Met-TiO2-650 (respectively 3.55 and $3.42 \mathrm{eV}$ ). Here also, the synthesis operating variables (molar [EDAP]/[TTIP] ratio, solvent nature and calcination temperature) have no influence on the band gap energy values.

\subsection{Photocatalytic Tests with Pure $\mathrm{TiO}_{2}$ and $\mathrm{P}$-Doped $\mathrm{TiO}_{2}$ Xerogels}

The photocatalytic activity of the $\mathrm{TiO}_{2}$ xerogels (pure and P-doped) examined for the PN degradation is presented in Figure 5 which firstly shows that all dried samples are inactive. With calcination the efficiency of the resulting materials highly increases reaching a maximum of 57\% in the case of sample Met-TiP/0.1-650. It also appears that phosphorus has a strong influence on the photocatatytic activity.

\section{Discussion}

\subsection{Thermal Evolution of Pure $\mathrm{TiO}_{2}$ and $\mathrm{P}$-Doped $\mathrm{TiO}_{2}$ Xerogels}

From TG-DSC measurements, the thermogravimetric behaviour of pure $\mathrm{TiO}_{2}$ and P-doped $\mathrm{TiO}_{2}$ xerogels was studied and allowed to define the different temperatures of calcination for samples. Nevertheless, since the operating variables between TG-DSC measurements and calcination are not strictly the same (heating rate, length of the temperature bearing, He for TG-DSC and air for calcination), the temperatures, for which thermal behaviours are examined, can be different for both cases [28].

For the blank Phophorus-free sample Met-TiO ${ }_{2}$, the TG-DSC and XRD measurements show three successive thermal behaviours: 1) the solvent and water, which are always present inside the pores of this sample even after drying under vacuum at $150^{\circ} \mathrm{C}$ for $24 \mathrm{~h}$, are evaporated below $250^{\circ} \mathrm{C}$, which corresponds to an important weight loss of sample (about 20\%); 2) the crystallization of amorphous $\mathrm{TiO}_{2}$ into anatase occurs at around $380^{\circ} \mathrm{C}$ [7] [15]; 3) the crystallization of anatase into rutile seems likely to occur between $550^{\circ} \mathrm{C}$ and $650^{\circ} \mathrm{C}$ [15]. Furthermore, two exothermic peaks at $300^{\circ} \mathrm{C}$ and $385^{\circ} \mathrm{C}$ (overlapping with the peak of crystallization of amorphous $\mathrm{TiO}_{2}$ into anatase) are present in Figure 1(a). These peaks are assigned to condensation reactions between hydroxyl groups or between hydroxyl groups and alkoxy groups [24]. The condensation in the gel is therefore not complete after $24 \mathrm{~h}$ at $60^{\circ} \mathrm{C}$ (gelling and aging [17]). Indeed, Bodson et al. [16], showed that 2-methoxyethanol used as solvent, can also act as a chelating ligand and hence the formation of chelated Ti-species by ligand exchange (Equation (2)) is expected. These are less reactive towards hydrolysis and condensation reactions.

$$
\mathrm{Ti}\left(\mathrm{O}-{ }^{\mathrm{i}} \mathrm{Pr}\right)_{\mathrm{n}}(\mathrm{OEtOMe})_{4-\mathrm{n}}+\mathrm{MeOEtOH} \leftrightarrow \mathrm{Ti}\left(\mathrm{O}-{ }^{\mathrm{i}} \mathrm{Pr}\right)_{\mathrm{n}-1}(\mathrm{OEtOMe})_{5-\mathrm{n}}+{ }^{\mathrm{i}} \mathrm{PrOH} \quad \mathrm{n}=1 \text { to } 4
$$




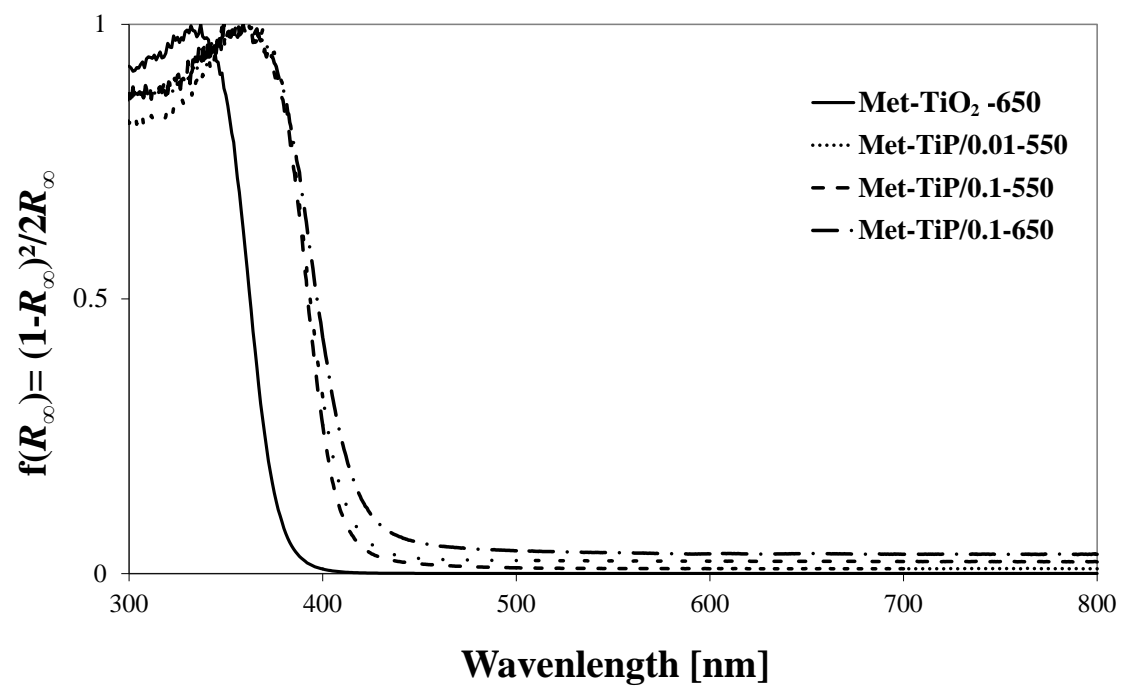

Figure 4. DR-UV/Vis spectra of pure $\mathrm{TiO}_{2}$ and $\mathrm{P}$-doped $\mathrm{TiO}_{2}$ xerogels.

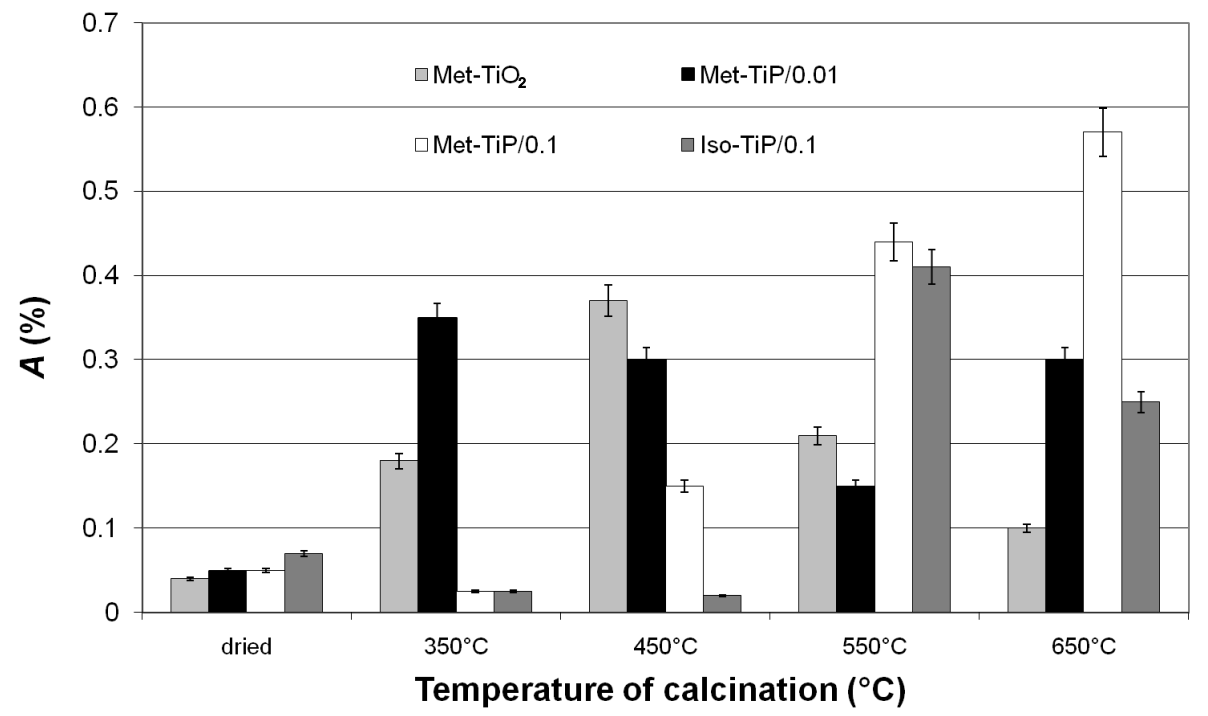

Figure 5. Percentage of PN degradation. $\mathrm{pH}=3.5$; 6 h of illumination.

Table 5. Band-gap energy (eV) calculated for all samples calcined at $550^{\circ} \mathrm{C}$ and $650^{\circ} \mathrm{C}$.

\begin{tabular}{ccccc}
\hline Sample & $\mathrm{Met}^{-\mathrm{TiO}_{2}}$ & Met-TiP/0.01 & Met-TiP/0.1 & Iso-TiP/0.1 \\
\hline Temperature $\left({ }^{\circ} \mathrm{C}\right)$ & & & & \\
550 & 3.55 & 3.10 & 3.05 & 3.10 \\
650 & 3.40 & 3.05 & 3.00 & 3.10 \\
\hline
\end{tabular}

Considering the P-doped samples (Met-TiP/0.01, Met-TiP/0.1 and Iso-TiP/0.1), the introduction of phosphorus modifies the crystallization temperatures of $\mathrm{TiO}_{2}$ (Figure 1(b) and Figure 2): 1) the exothermic peak corresponding to the crystallization of amorphous $\mathrm{TiO}_{2}$ into anatase, appears at significantly high temperature $\left(550^{\circ} \mathrm{C}\right)$ for the samples with higher phosphorus content (Met-TiP/0.1 and Iso-TiP/0.1); this crystallization temperature decreases to $420^{\circ} \mathrm{C}$ for sample Met-TiP/0.01 and is even lower $\left(385^{\circ} \mathrm{C}\right.$ ) for the P-free sample $\mathrm{Met}^{-T i O}$. It is clear that the presence of phosphorus in the $\mathrm{TiO}_{2}$ matrix delays the transformation of amorphous $\mathrm{TiO}_{2}$ into crystalline anatase. A longer crystallization delay is observed on increasing the phosphorus loading [5] [27]. Nevertheless, the nature of solvent (2-methoxyethanol or isopropanol) has no influence on the $\mathrm{TiO}_{2} \mathrm{crystalliza-}$ 
tion temperature; 2) even after calcination at $650^{\circ} \mathrm{C}$, no rutile phase is detected in P-doped $\mathrm{TiO}_{2}$ xerogels, contrarily to the sample Met- $\mathrm{TiO}_{2}$, for which the rutile phase is detected when calcined at $650^{\circ} \mathrm{C}$ [15]. These results were also observed by Körösi et al. [28] for P-doped $\mathrm{TiO}_{2}$ materials with molar P/Ti ratios $=0.01$ and 0.1 . The presence of phosphorus stabilizes the anatase structure, which is very interesting since anatase is the most effective structure of $\mathrm{TiO}_{2}$ in photocatalysis. Previously, $\mathrm{H}_{3} \mathrm{PO}_{4}$-doped $\mathrm{TiO}_{2}$ xerogels were reported and in this case, the rutile structure is obtained for temperatures $>900^{\circ} \mathrm{C}$ with a molar P/Ti ratio of 0.05 , and $>1000^{\circ} \mathrm{C}$ with a molar P/Ti ratio of 0.1 to 0.5 [29].

Myller et al. [30] showed that [2-(aminoethyl)dihydrogeno]phosphate and [2-(aminoethyl)hydrogenoammonium]phosphate, two similar molecules to EDAP, are decomposed around $300^{\circ} \mathrm{C}-350^{\circ} \mathrm{C}$ in P-doped $\mathrm{TiO}_{2}$ materials when these molecules are free and not bonded to $\mathrm{TiO}_{2}$. In Bodson et al. [16], it was shown by Raman and Solid ${ }^{31} \mathrm{P}$ NMR spectroscopies, that the EDAP fragment is maintained within the $\mathrm{TiO}_{2}$ structure, either by complexation of titanium atoms with the ethylenediamine fragment of EDAP, or by covalent linkage through P-OTi bonds. So EDAP molecules only complexed to titanium atoms can sublimate when temperature increases. These results are confirmed by ICP-AES measurements (Table 2), for which a loss of phosphorus is observed for all P-doped $\mathrm{TiO}_{2}$ xerogels when the calcination temperature increases.

It is observed that the size of $\mathrm{TiO}_{2}$-anatase crystallites, $d_{\mathrm{a}}$, increases with the calcination temperature for all the samples (Table 3). But the growth of $\mathrm{TiO}_{2}$-anatase crystallites slows down when the molar P/Ti ratio increases [31]. Indeed, after calcination at $650^{\circ} \mathrm{C}, d_{\mathrm{a}}$ is equal to $19 \mathrm{~nm}$ for the sample Met-TiP/0.01-650, while $d_{\mathrm{a}}$ is around $10 \mathrm{~nm}$ for the samples Met-TiP/0.1-650 and Iso-TiP/0.1-650.

In opposite to the nitrogen adsorption-desorption measurements for dried P-doped $\mathrm{TiO}_{2}$ xerogels [15], the nature of solvent (2-methoxyethanol or isopropanol) is not the key factor, which influences the porous texture of xerogels (Table 4). In this work, it seems that the molar P/Ti ratio is the more important factor. Such an influence can be due to either to the influence of phosphorus on surface area, crystallite anatase size, and/or intrinsic influence of Ti-O-P bond formation. To distinguish between both effects, three models are developed below to find any correlations between activity and physico-chemical properties.

\subsection{Parameter Adjustment}

After examination of Figure 5 representing the activity of pure $\mathrm{TiO}_{2}$ and $\mathrm{P}$-doped $\mathrm{TiO}_{2}$ xerogels for the PN degradation, it is not possible to determine what are the physico-chemical properties - the phosphor rate, the anatase crystallite size and the specific area — that intrinsically influence the phosphor doped $\mathrm{TiO}_{2}$ xerogel activity. In order to establish correlations between the phosphor rate, the anatase crystallite size, the specific area and the photocatalytic activity, parameter adjustments and a statistical data treatment were performed on $\mathrm{TiO}_{2}$-anatase xerogel samples calcinated at $550^{\circ} \mathrm{C}$ and $650^{\circ} \mathrm{C}$. The considered samples are listed in Table 6 with their photocatalytic activity and their physico-chemical properties.

The main question is to determine if the photocatalytic activity of the $\mathrm{TiO}_{2}$ xerogels doped with phosphor only depends on the particle size and on the specific area varying with amount of EDAP used during synthesis, or if the phosphor rate intrinsically influences the photocatalytic activity. In order to answer the question of the phosphor influence, three models have been adjusted on experimental data. The first model, named Model 1 , describes the photocatalytic activity, $A$, as a function of the molar ratio P/Ti, $P$, only. The second model, named Model 2, describes $A$ as a function of the particle size, $d_{\mathrm{a}}$, and of the specific area, $S_{\mathrm{BET}}$. The last model, named

Table 6. Physico-chemical properties and catalytic activity of all samples calcined at $550^{\circ} \mathrm{C}$ and $650^{\circ} \mathrm{C}$.

\begin{tabular}{cccccc}
\hline & Sample & $\begin{array}{c}P \\
(\mathrm{~mol} / \mathrm{mol})\end{array}$ & $\begin{array}{c}d_{\mathrm{a}} \\
(\mathrm{nm})\end{array}$ & $\begin{array}{c}S_{\mathrm{BET}} \\
\left(\mathrm{m}^{2} \cdot \mathrm{g}^{-1}\right)\end{array}$ & $\begin{array}{c}A \\
(\%)\end{array}$ \\
\hline 1 & Met-TiO $_{2}-550$ & - & 24 & $<5$ & 21 \\
2 & Met-TiP/0.01-550 & 0.0028 & 14 & 40 & 18 \\
3 & Met-TiP/0.01-650 & 0.0056 & 19 & 35 & 29 \\
4 & Met-TiP/0.1-550 & 0.0710 & 8 & 105 & 44 \\
5 & Met-TiP/0.1-650 & 0.0724 & 8 & 90 & 57 \\
6 & Iso-TiP/0.1-550 & 0.0932 & 10 & 40 & 41 \\
7 & Iso-TiP/0.1-650 & 0.0246 & 13 & 45 & 25 \\
\hline
\end{tabular}


Model 3, describes $A$ as a function of the three previous variables $P, d_{\mathrm{a}}$ and $S_{\mathrm{BET}}$ simultaneously.

$$
\begin{array}{ll}
\text { Model 1: } & A=\mathrm{f}_{1}(P)=\mathrm{a}_{0}+\mathrm{a}_{1} P+\mathrm{a}_{2} P^{2} \\
\text { Model 2: } & A=\mathrm{f}_{2}\left(d_{\mathrm{a}}, S_{\mathrm{BET}}\right)=\mathrm{b}_{0}+\mathrm{b}_{1} d_{\mathrm{a}}+\mathrm{b}_{2} S_{\mathrm{BET}} \\
\text { Model 3: } & A=\mathrm{f}_{3}\left(P, d_{\mathrm{a}}, S_{\mathrm{BET}}\right)=\mathrm{c}_{0}+\mathrm{c}_{1} P+\mathrm{c}_{2} d_{\mathrm{a}}+\mathrm{c}_{3} S_{\mathrm{BET}}
\end{array}
$$

where $\mathrm{a}_{0}, \mathrm{a}_{1}, \mathrm{a}_{2}$ are the parameters of Model $1, \mathrm{~b}_{0}, \mathrm{~b}_{1}, \mathrm{~b}_{2}$ are the parameters of Model 2 and $\mathrm{c}_{0}, \mathrm{c}_{1}, \mathrm{c}_{2}, \mathrm{c}_{3}$ are the parameters of Model 3.

In order to determine which model better fits on experimental data, a statistical Fisher $F$-test was performed with a 75\% confidence interval. Models 1 and 2 include 3 parameters, while Model 3 includes 4 parameters. So the number of degrees of freedom of Models 1 and 2 and of Model 3 is respectively equal to 4 and 3 because 7 experimental points have been used for parameter adjustment. The estimators of the residual variance are equal to 68, 126 and 49 for Models 1, 2 and 3 respectively. The ratio between the estimators of the residual variance of Models 1 and 3 is equal to 1.39 and the ratio between the estimators of the residual variance of Models 2 and 3 is equal to 2.57. However, the Fischer variable $F(0.25,4,3)$ is equal to 2.4 , which is greater than 1.39 and smaller than 2.57, meaning that Model 2 can be rejected while Models 1 and 3 cannot be discriminated. Figure 6 compares the photocatalytic activity calculated with models 1,2 and 3 with the experimental photocatalytic activity. Points corresponding to Models 1 and 3 are better aligned along the bisector than points corresponding to Model 2, in agreement with the statistical Fischer F-test. So because Model 2 describes $A$ as a function of $d_{\mathrm{a}}$ and of $S_{\mathrm{BET}}$ only, it can be stated that phosphor intrinsically influences the photocatalytic activity, probably by extending the light adsorption to the visible range.

One last question remains till in mind: why Model 1 depending on $P$ only, and Model 3 depending on $P, d_{\mathrm{a}}$ and $S_{\mathrm{BET}}$ simultaneously, are not statistically discriminatory. The explanation comes from the dependence of $d_{\mathrm{a}}$ and $S_{\mathrm{BET}}$ on $P$.

Figure 7 represents the experimental photocatalytic activity $A$ as a function of $P$. A second degree expression corresponding to Model 1 and passing through a maximum is adjusted. According to Yu et al. [29], the maximum can be explained by the fact that a too high $P$ value improves the formation of $\mathrm{TiP}_{2} \mathrm{O}_{7}$ species inhibiting the $\mathrm{TiO}_{2}$ photocatalytic activity.

Because Model 1, depending on $P$ only, and Model 3, depending on $P, d_{\mathrm{a}}$ and $S_{\mathrm{BET}}$, are not statistically different, it seems that $d_{\mathrm{a}}$ and $S_{\mathrm{BET}}$ only depends on $P$. Figure 8 represents the anatase particle size $d_{\mathrm{a}}$ as a function of $P$ and the relation between $d_{\mathrm{a}}$ and $P$ is modelled by:

$$
d_{\mathrm{a}}=\mathrm{d}_{0}+\mathrm{d}_{1} P+\mathrm{d}_{2} P^{2}
$$

where $\mathrm{d}_{0}, \mathrm{~d}_{1}, \mathrm{~d}_{2}$ are the coefficients of the equation. The particle size $d_{\mathrm{a}}$ increases when $P$ increases, reaches a maximum for a $P$ value around 0.07 before decreasing for higher $P$ values. The optimal $P$ value of 0.07 corresponds to the maximum photocatalytic activity observed in Figure 7. Those results are in agreement with Zheng et al. observations that highlighted that above $P$ equal to 0.08 , the increase of $P$ inhibits the particle growth [31].

Figure 9 represents the specific surface area, $S_{\mathrm{BET}}$, as a function of $P$ and the relation between $S_{\mathrm{BET}}$ and $P$ is modelled by:

$$
S_{\text {BET }}=\mathrm{e}_{0}+\mathrm{e}_{1} P+\mathrm{e}_{2} P^{2}
$$

where $\mathrm{e}_{0} \mathrm{e}_{1}, \mathrm{e}_{2}$ are the coefficients of the Equation (7). The specific surface area, $S_{\mathrm{BET}}$, increases when $P$ increases, reaches a maximum for a $P$ value of around 0.06 before decreasing for higher $P$ values. The optimal $P$ value of 0.06 approximately corresponds to the maximum photocatalytic activity observed in Figure 7 . Those results are in agreement with literature that places the optimal $P$ value between 0.05 and 0.1 [29] [31].

So Equation (6) and Equation (7) describe $d_{\mathrm{a}}$ and $S_{\mathrm{BET}}$ as a function of $P$ only, according to a second degree relation. Furthermore, Model 3 is linear with $P, d_{\mathrm{a}}$ and $S_{\mathrm{BET}}$, meaning that Model 3 can be assimilated to a second degree equation as a function of $P$. This explains why Models 1 and 3 are not statistically discriminatory and proves that phosphor intrinsically influences the photocatalytic activity.

\section{Conclusions}

The $\mathrm{TiO}_{2}$-anatase structure in $\mathrm{P}$-doped $\mathrm{TiO}_{2}$ xerogels appears after calcination at $550^{\circ} \mathrm{C}$ and is always present af- 


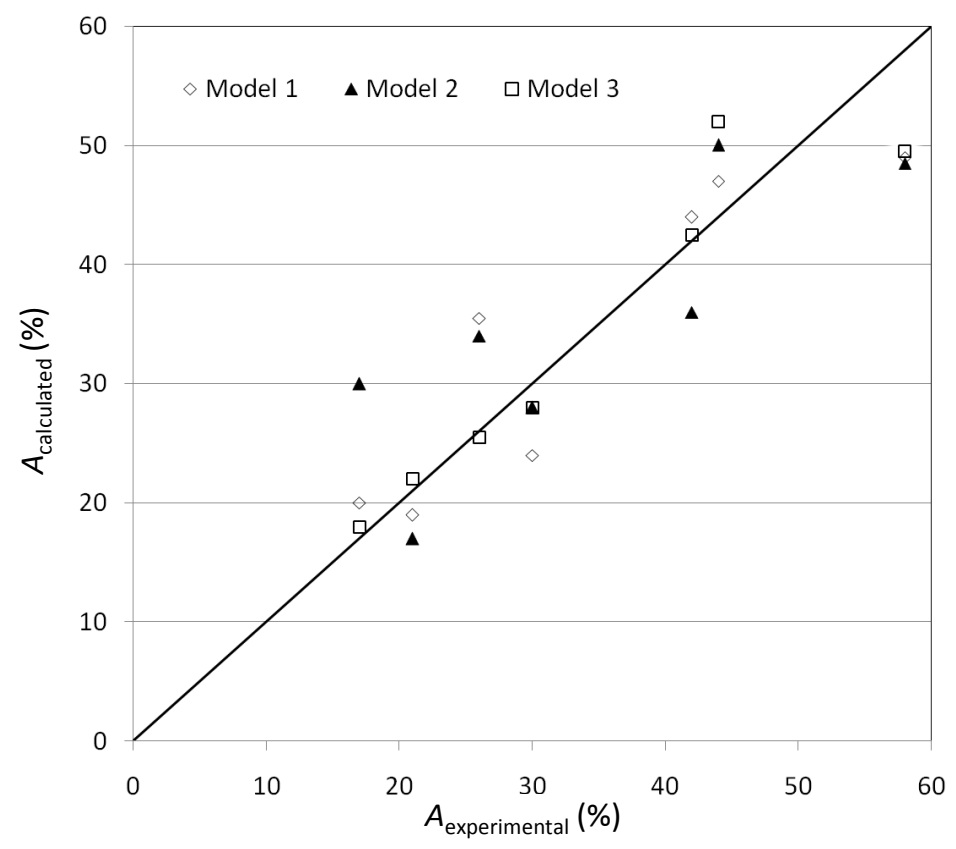

Figure 6. Parity diagram for Model $1\left(A=\mathrm{f}_{1}(P)\right)(\diamond)$, Model $2\left(A=\mathrm{f}_{2}\left(d_{\mathrm{a}}\right.\right.$, $\left.\left.S_{\mathrm{BET}}\right)\right)(\boldsymbol{\Delta})$ and Model $3\left(A=\mathrm{f}_{3}\left(\mathrm{P}, d_{\mathrm{a}}, S_{\mathrm{BET}}\right)\right)(\square)$.

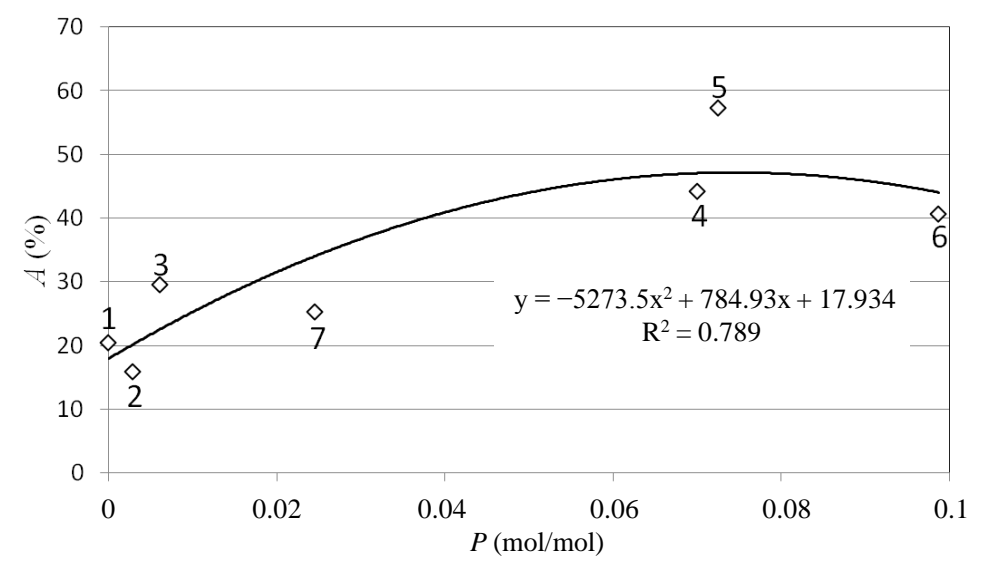

Figure 7. Photocatalytic activity as a function of $P$ for the PN degradation. Points correspond to experimental data, the line corresponds to parameter adjustment and numbers correspond to samples listed in Table 6.

ter calcination at $650^{\circ} \mathrm{C}$, while the $\mathrm{TiO}_{2}$-anatase in pure $\mathrm{TiO}_{2}$ xerogels appears from $350^{\circ} \mathrm{C}$ and after calcination at $650^{\circ} \mathrm{C}$, anatase is completely transformed in $\mathrm{TiO}_{2}$-rutile. For photocatalytic $p$-nitrophenol degradation, Pdoped $\mathrm{TiO}_{2}$ xerogels are more active than pure $\mathrm{TiO}_{2}$ xerogels. Indeed, the $p$-nitrophenol degradation percentage reachs $35 \%$ for the pure $\mathrm{TiO}_{2}$ xerogel, while it reachs 55\% for $\mathrm{P}$-doped $\mathrm{TiO}_{2}$ xerogels (sample Met-TiP/0.1-650).

In this study, it was established that the relations between the physico-chemical properties and the photocatalytic activity of P-doped $\mathrm{TiO}_{2}$ xerogels strongly depend of the molar P/Ti ratio. The photocatalytic activity also depends to the size of $\mathrm{TiO}_{2}$-anatase crystallites and to the specific surface area of xerogels: xerogels are even more active for the $p$-nitrophenol degradation that the size of $\mathrm{TiO}_{2}$-anatase crystallites is small and the specific surface area is high.

\section{Acknowledgements}

Two of us (S.L.P and S.D.L.) are grateful to F.R.S.-F.N.R.S for their postdoctoral research and research asso- 


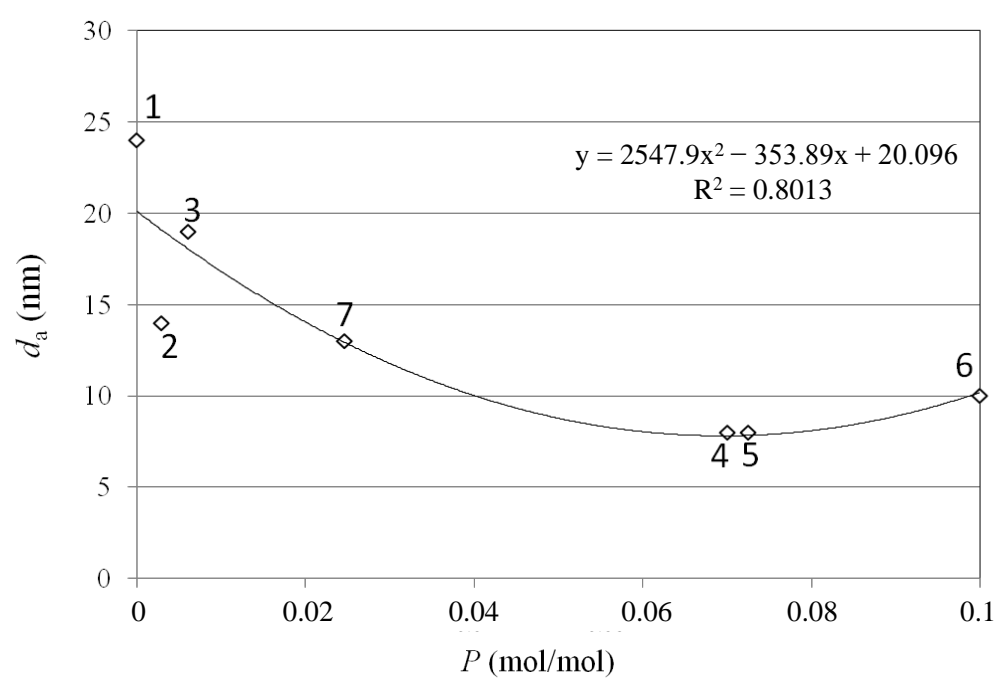

Figure 8. Diameter of $\mathrm{TiO}_{2}$-anatase crystallites, $d_{\mathrm{a}}$, as a function of $P$. Points correspond to experimental data, the line corresponds to parameter adjustment and numbers correspond to samples listed in Table 6.

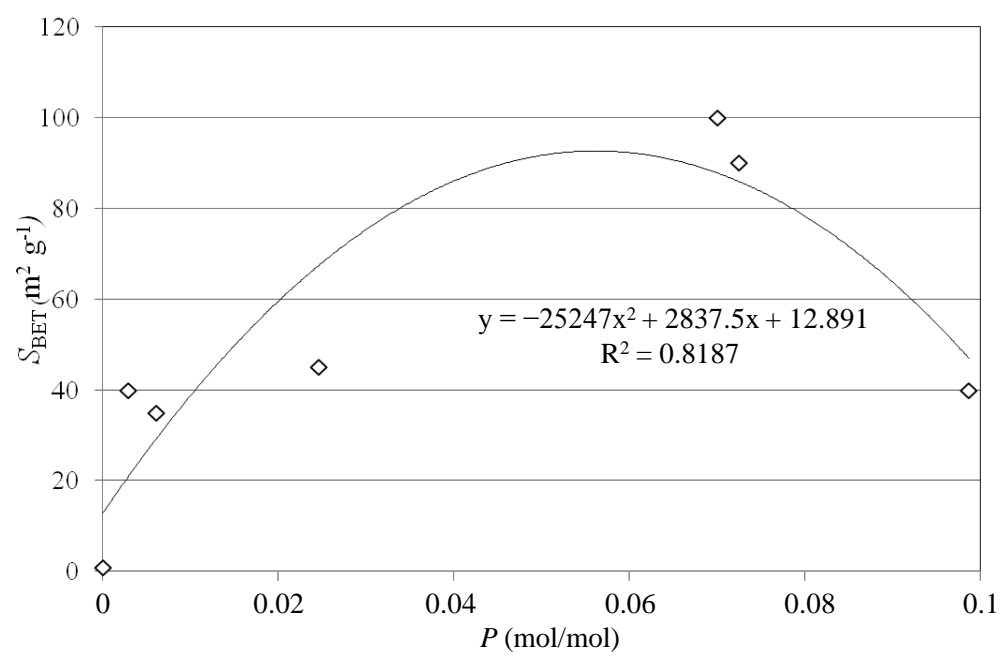

Figure 9. Specific surface area, $S_{\mathrm{BET}}$, of $\mathrm{TiO}_{2}$-anatase crystallites as a function of $P$. Points correspond to experimental data, the line corresponds to parameter adjustment and numbers correspond to samples listed in Table 6.

ciate positions respectively. One of us (L.T.) is grateful to the Belgian Fonds pour la Formation à la Recherche dans l'Industrie et dans l'Agriculture, F.R.I.A., and the University of Liege for a $\mathrm{PhD}$ grant. The authors would like to thank Pr. Jean-Paul Pirard, University of Liege (Belgium), and Pr. Dirk Poelman, University of Ghent (Belgium), for helpful discussions. The authors also acknowledge the Ministère de la Région Wallonne Direction Générale des Technologies, de la Recherche et de l’Energie, the Fonds de Recherche Fondamentale Collective and the Interuniversity Attraction Pole (IAP-P6/17), the FAME Network of Excellence and the French "Ministère des affaires étrangères et européennes” (PHC Tournesol) for financial supports.

\section{References}

[1] Fujishima, A., Rao, T.N. and Tryk, D.A. (2000) Titanium Dioxide Photocatalysis. Journal of Photochemistry and Photobiology C: Photochemistry Reviews, 1, 1-21.

[2] Gaya, U.I. and Abdullah, A.H. (2008) Heterogeneous Photocatalytic Degradation of Organic Contaminants over Titanium Dioxide: A Review of Fundamentals, Progress and Problems. Journal of Photochemistry and Photobiology C: 
Photochemistry Reviews, 9, 1-12. http://dx.doi.org/10.1016/j.jphotochemrev.2007.12.003

[3] Mills, A. and Le Hunte, S. (1997) An Overview of Semiconductor Photocatalysis. Journal of Photochemistry and Photobiology A: Chemistry, 108, 1-35. http://dx.doi.org/10.1016/S1010-6030(97)00118-4

[4] Lv, Y., Yu, L., Huang, H., Liu, H. and Feng, Y. (2009) Preparation, Characterization of P-Doped TiO ${ }_{2} \mathrm{Nanoparticles}$ and Their Excellent Photocatalystic Properties under the Solar Light Irradiation. Journal of Alloys and Compounds, 488, 314-319. http://dx.doi.org/10.1016/j.jallcom.2009.08.116

[5] Lin, L., Zheng, R.Y., Xie, J.L., Zhu, Y.X. and Xie, Y.C. (2007) Synthesis and Characterization of Phosphor and Nitrogen Co-Doped Titania. Applied Catalysis B: Environmental, 76, 196-202. http://dx.doi.org/10.1016/j.apcatb.2007.05.023

[6] Xu, L., Tang, C.Q., Qian, J., Huang, Z. B. (2010) Theoretical and Experimental Study on the Electronic Structure and Optical Absorption Properties of P-Doped $\mathrm{TiO}_{2}$. Applied Surface Science, 256, 2668-2671. http://dx.doi.org/10.1016/j.apsusc.2009.11.046

[7] Yu, J., Yu, J.C., Ho, W., Leung, M.P.K., Cheng, B., Zhang, G. and Zhao, X. (2003) Effects of Alcohol Content and Calcination Temperature on the Textural Properties of Bimodally Mesoporous Titania. Applied Catalysis A: General, 255, 309-320. http://dx.doi.org/10.1016/S0926-860X(03)00570-2

[8] Stafford, U., Gray, K.A., Kamat, P.V. and Varma, A. (1993) An in Situ Diffuse Reflectance FTIR Investigation of Photocatalytic Degradation of 4-Chlorophenol on a $\mathrm{TiO}_{2}$ Powder Surface. Chemical Physics Letters, 205, 55-61. http://dx.doi.org/10.1016/0009-2614(93)85166-L

[9] Yoo, K.S., Lee, T.G. and Kim, J. (2005) Preparation and Characterization of Mesoporous $\mathrm{TiO}_{2}$ Particles by Modified Sol-Gel Method Using Ionic Liquids. Microporous and Mesoporous Materials, 84, 211-217. http://dx.doi.org/10.1016/j.micromeso.2005.05.029

[10] Simonsen, M. and Søgaard, E. (2010) Sol-Gel Reactions of Titanium Alkoxides and Water: Influence of pH and Alkoxy Group on Cluster Formation and Properties of the Resulting Products. Journal of Sol-Gel Science and Technology, 53, 485-497. http://dx.doi.org/10.1007/s10971-009-2121-0

[11] Terabe, K., Kato, K., Miyazaki, H., Yamaguchi, S., Imai, A. and Iguchi, Y. (1994) Microstructure and Crystallization Behaviour of $\mathrm{TiO}_{2}$ Precursor Prepared by the Sol-Gel Method Using Metal Alkoxide. Journal of Materials Science, 29, 1617-1622. http://dx.doi.org/10.1007/BF00368935

[12] Li, Z., Hou, B., Xu, Y., Wu, D., Sun, Y., Hu, W. and Deng, F. (2005) Comparative Study of Sol-Gel-Hydrothermal and Sol-Gel Synthesis of Titania-Silica Composite Nanoparticles. Journal of Solid State Chemistry, 178, 1395-1405. http://dx.doi.org/10.1016/j.jssc.2004.12.034

[13] Wang, C.Y., Bahnemann, D.W. and Dohrmann, J.K. (2000) A Novel Preparation of Iron-Doped TiO ${ }_{2} \mathrm{Nanoparticles}^{2}$ with Enhanced Photocatalytic Activity. Chemical Communications, 16, 1539-1540. http://dx.doi.org/10.1039/b002988m

[14] Sibu, C.P., Kumar, S.R., Mukundan, P. and Warrier, K.G.K. (2002) Structural Modifications and Associated Properties of Lanthanum Oxide Doped Sol-Gel Nanosized Titanium Oxide. Chemistry of Materials, 14, 2876-2881. http://dx.doi.org/10.1021/cm010966p

[15] Braconnier, B., Páez, C.A., Lambert, S., Alié, C., Henrist, C., Poelman, D., Pirard, J.P., Cloots, R. and Heinrichs, B. (2009) Ag- and $\mathrm{SiO}_{2}$-Doped Porous $\mathrm{TiO}_{2}$ with Enhanced Thermal Stability. Microporous and Mesoporous Materials, 122, 247-254. http://dx.doi.org/10.1016/j.micromeso.2009.03.007

[16] Bodson, C.J., Lambert, S.D., Alié, C., Cattoën, X., Pirard, J.P., Bied, C., Manb, M.W.C. and Heinrichs, B. (2010) Effects of Additives and Solvents on the Gel Formation Rate and on the Texture of P- and Si-Doped $\mathrm{TiO}_{2} \mathrm{Materials}$ Microporous and Mesoporous Materials, 134, 157-164. http://dx.doi.org/10.1016/j.micromeso.2010.05.021

[17] Brinker, C.J. and Scherer, G.W. (1990) Sol-Gel Science: The Physics and Chemistry of Sol-Gel Processing. Academic Press, San Diego.

[18] Bergeret, G. and Gallezot, P. (1997) Particle Size and Dispersion Measurements. In: Ertl, G., Knözinger, H., Schuth, F. and Weitkamp, J., Eds., Handbook of Heterogeneous Catalysis, Wiley-VCH, Weinheim, 439-464.

[19] Kubelka, P. and Munk, F. (1931) Ein Beitrag Zur Optik Der Farbanstriche. Zeitschrift für Technische Physik, 12, 593-601.

[20] Tauc, J., Grigorovici, R. and Vancu, A. (1966) Optical Properties and Electronic Structure of Amorphous Germanium. Physica Status Solidi (b), 15, 627-637. http://dx.doi.org/10.1002/pssb.19660150224

[21] Himmelblau, D.M. (1970) Process Analysis by Statistical Methods. Wiley, New York.

[22] Press, W.H., Flannery, B.P., Teukolsky, S.A. and Vetterling, W.T. (1990) Numerical Recipes in C-The Art of Scientific Computing. Cambridge University Press, Cambridge.

[23] Pirard, S., Pirard, J.P., Heyen, G., Schoebrechts, J.P. and Heinrichs, B. (2011) Experimental Procedure and Statistical 
Data Treatment for the Kinetic Study of Selective Hydrodechlorination of 1,2-Dichloroethane into Ethylene over a Pd-Ag Sol-Gel Catalyst. Chemical Engineering Journal, 173, 801-812. http://dx.doi.org/10.1016/j.cej.2011.07.002

[24] Stojanović, B., Marinković, Z., Branković, G. and Fidančevska, E. (2000) Evaluation of Kinetic Data for Crystallization of $\mathrm{TiO}_{2}$ Prepared by Hydrolysis Method. Journal of Thermal Analysis and Calorimetry, 60, 595-604. http://dx.doi.org/10.1023/A:1010107423825

[25] Lachheb, H., Houas, A. and Herrmann, J.M. (2008) Photocatalytic Degradation of Polynitrophenols on Various Commercial Suspended or Deposited Titania Catalysts Using Artificial and Solar Light. International Journal of Photoenergy, 2008, Article ID: 497895, 9 Pages.

[26] Lecloux, A.J. (1981) Texture of Catalysts. In: Anderson, J.R. and Boudart, M., Eds., Catalysis: Science and Technology, Vol. 2, Springer, Berlin, 171-230.

[27] Li, F.F., Jiang, Y.S., Xia, M.S., Sun, M.M., Xue, B., Liu, D.R. and Zhang, X.G. (2009) Effect of the P/Ti Ratio on the Visible-Light Photocatalytic Activity of P-Doped $\mathrm{TiO}_{2}$. The Journal of Physical Chemistry C, 113, 18134-18141. http://dx.doi.org/10.1021/jp902558z

[28] Körösi, L., Papp, S., Bertóti, I. and Dékány, I. (2007) Surface and Bulk Composition, Structure, and Photocatalytic Activity of Phosphate-Modified $\mathrm{TiO}_{2}$. Chemistry of Materials, 19, 4811-4819. http://dx.doi.org/10.1021/cm070692r

[29] Yu, H.F. (2007) Photocatalytic Abilities of Gel-Derived P-Doped $\mathrm{TiO}_{2}$. Journal of Physics and Chemistry of Solids, 68, 600-607. http://dx.doi.org/10.1016/j.jpcs.2007.01.050

[30] Myller, A.T., Karhe, J.J. and Pakkanen, T.T. (2010) Preparation of Aminofunctionalized $\mathrm{TiO}_{2}$ Surfaces by Binding of Organophosphates. Applied Surface Science, 257, 1616-1622. http://dx.doi.org/10.1016/j.apsusc.2010.08.109

[31] Zheng, R.Y., Lin, L., Xie, J.L., Zhu, Y.X. and Xie, Y.C. (2008) State of Doped Phosphorus and Its Influence on the Physicochemical and Photocatalytic Properties of P-Doped Titania. The Journal of Physical Chemistry C, 112, 1550215509. http://dx.doi.org/10.1021/jp806121m 
Scientific Research Publishing (SCIRP) is one of the largest Open Access journal publishers. It is currently publishing more than 200 open access, online, peer-reviewed journals covering a wide range of academic disciplines. SCIRP serves the worldwide academic communities and contributes to the progress and application of science with its publication.

Other selected journals from SCIRP are listed as below. Submit your manuscript to us via either submit@scirp.org or Online Submission Portal.
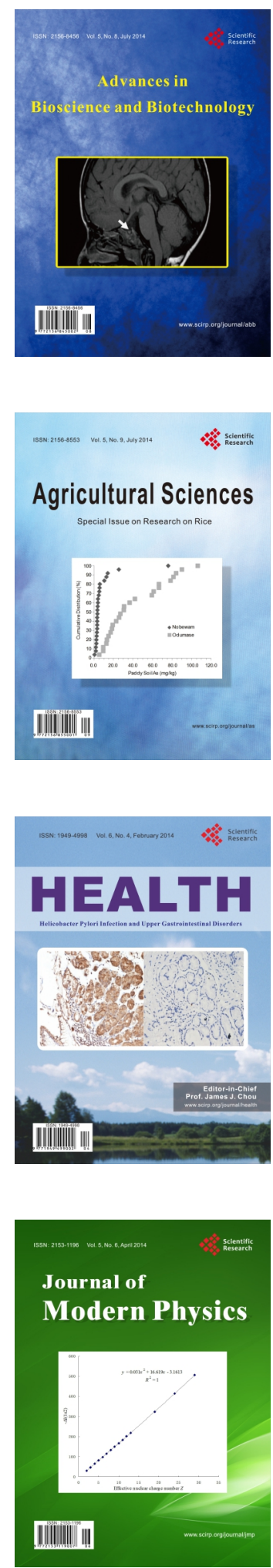
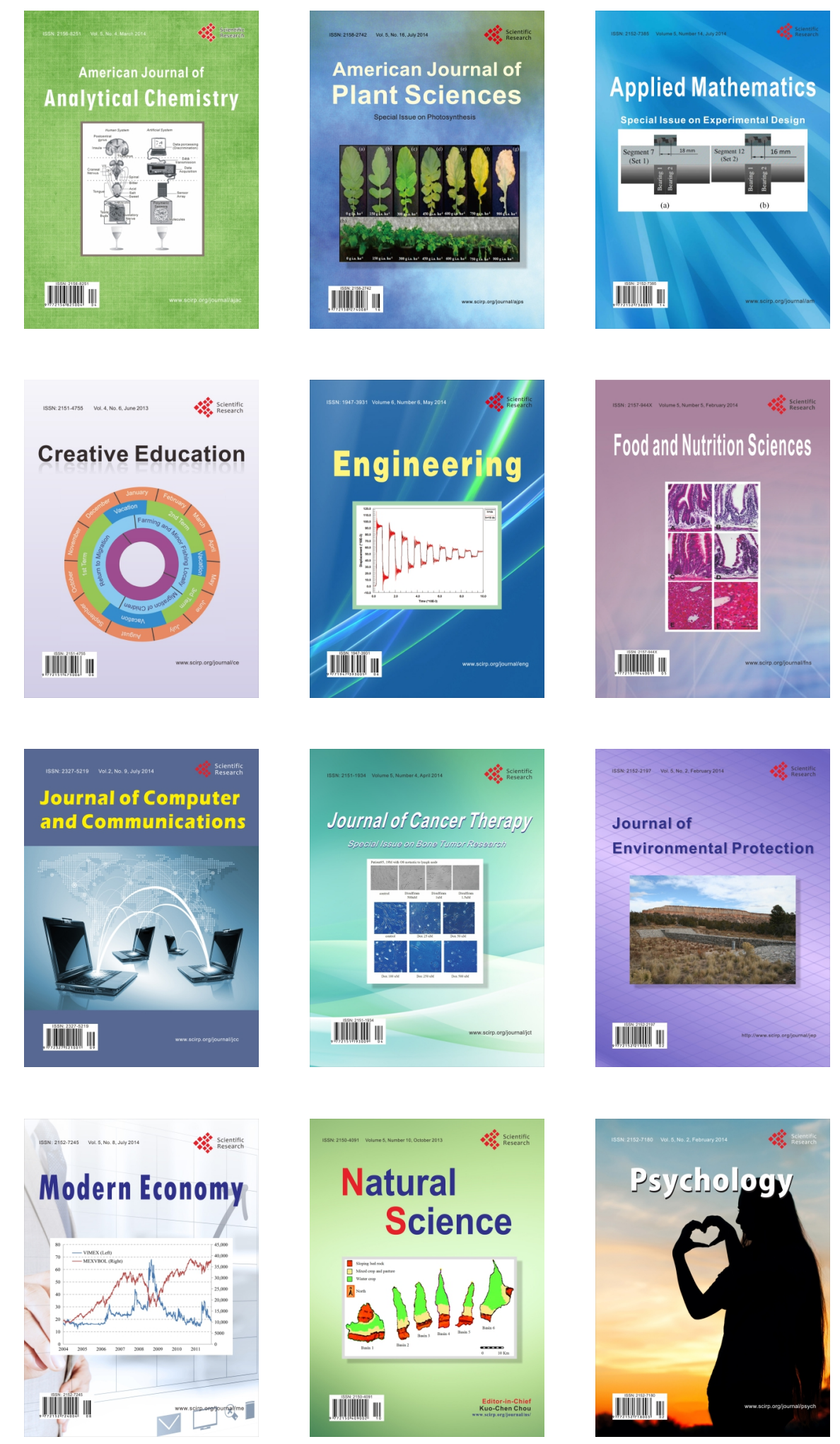